\title{
GENETIC STUDIES ON CYCLOHEXIMIDE-RESISTANT STRAINS OF SCHIZOSACCHAROMYCES POMBE
}

\author{
MOHAMMED A. K. IBRAHIM and ALAN CODDINGTON \\ School of Biological Sciences, University of East Anglia, Norwich NR4 7TJ \\ Received 4.ii.76
}

\begin{abstract}
SUMMARY
Cycloheximide-resistant mutants of Schizosaccharomyces pombe were isolated either as spontaneous mutants or after mutagenic treatment with nitrous acid, UV and N-methyl-N'-nitro-N-nitrosoguanidine (MNNG). Twenty-three spontaneous mutants and 64 induced mutants were analysed genetically. Crosses revealed that at least four loci, designated $c y h 1, c y h 2, c y h 3$ and $c y h 4$ are responsible for resistance. Alleles of $c y h \mathrm{l}$ show good growth on either high $(100 \mu \mathrm{g} / \mathrm{ml})$ or low $(40 \mu \mathrm{g} / \mathrm{ml})$ concentrations of cycloheximide whereas alleles at the $c y h 2$, $c y h 3$ and cyh 4 loci grow well on $40 \mu \mathrm{g} / \mathrm{ml}$ but poorly on $100 \mu \mathrm{g} / \mathrm{ml}$. Some alleles at the $c y h 2$ and $c y h 3$ loci are also temperature sensitive $(t s)$, the $t s$ phenotype being conferred by the same gene as the resistance. In diploids, $c y h \mathrm{I}$ and $c y h 4$ are recessive to wild type whereas $c y h 2$ and $c y h 3$ are semi-dominant. There was no intragenic complementation between three $c y h 1$ alleles. Crossresistance to trichodermin and anisomycin was shown by cyh2, cyh 3 and cyh 4 but not $c y h 1$. Most $c y h 1$ alleles, of spontaneous and UV origin only, were cold sensitive $(c s)$ at $14^{\circ}$ and some of these were also cycloheximide dependent at the same temperature. It is suggested that the $c y h \mathrm{l}$ and $c y h 4$ genes are involved in ribosome formation or function and the other loci probably affect the uptake of cycloheximide by the cells.
\end{abstract}

\section{INTRODUGTION}

Cycloheximide (otherwise known as actidione) is a potent inhibitor of protein synthesis in eukaryotes and has been used to select resistant mutants in a wide variety of lower eukaryotic species. Cycloheximide-resistant strains have arisen either spontaneously or after mutagenic treatment in Saccharomyces cerevisiae (Middlekauf et al., 1957; Wilkie and Lee, 1965; Brusick, 1972), Neurospora crassa (Howe and Terry, 1962; Hsu, 1963; Neuhäuser et al., 1970; Vomvoyanni, 1974), Physarum polycephalum amoebae (Dee, 1966; Dee and Poulter, 1970; Haugli et al., 1972), Aspergillus nidulans (Warr and Roper, 1965; Waldron and Roberts, 1974) and Tetrahymena pyriformis (Roberts and Orias, 1973). In each of the above organisms resistance to cycloheximide was found to be conferred by more than one gene, with phenotypic expression varying from recessivity through semidominance to dominance. Furthermore, segregation was always mendelian and the genes therefore nuclear rather than cytoplasmic in origin. In view of the known effect of cycloheximide on protein synthesis it seemed likely that resistance to cycloheximide was a ribosomal property. This was first demonstrated by Siegel and Sisler (1965), who took advantage of the fact that one species of yeast Kluyveromyces fragilis (then wrongly classified as Saccharomyces fragilis) was resistant to $1000 \mu \mathrm{g} / \mathrm{ml}$ of antibiotic whereas growth of another species, Saccharomyces pastorianus, was completely inhibited by $0.17 \mu \mathrm{g} / \mathrm{ml}$. By using various combinations of ribosomes and supernatant fractions from the two species in a poly-U directed cell free 
system, they were able to show that resistance was a property of the ribosome and not the supernatant fraction. This work was later extended by Rao and Grollman (1967), who showed that resistance in $K$. fragilis was a property of the $60 \mathrm{~S}$ subunit. Studies on cycloheximide-resistant mutant strains of S. cerevisiae gave similar results. Cooper et al. (1967) showed that a cyh8 mutant had resistant ribosomes and Jimenez et al. (1972) that a cyh 2 mutant also had resistant ribosomes and furthermore that resistance was due to the $60 \mathrm{~S}$ subunit. Both the $c y h 8$ and $c y h 2$ strains used were resistant to high levels of cycloheximide and the resistance phenotype was recessive in diploids. Resistance to cycloheximide has also been shown to be a property of the ribosome in certain mutants of Neurospora (Pongratz and Klingmüller, 1973; Vomvoyanni, 1974) and Physarum (Haugli et al., 1972). Drug resistance could also be due, for instance, to an alteration in an uptake system or to the production of an enzyme which destroys the drug. Hence it is to be expected that in a search for resistant mutants many genes will be involved and not all of these will exert their primary effect at the level of the ribosome.

In an attempt to get suitable mutants for biochemical analysis, to increase the chromosomal markers available, and to study the genetic factors which cause cycloheximide resistance in the fission yeast Schizosaccharomyces pombe, we have isolated resistant mutants arising both spontaneously and after mutagenic treatment with UV, nitrous acid and MNNG. At least four genes, $c y h l, c y h 2, c y h 3$ and $c y h 4$, appear to be involved and two of these, cyhl and cyh4, are likely to affect ribosomal formation or function. A preliminary report of this work has already appeared (Ibrahim and Coddington, 1974).

\section{Materials and methods}

\section{(i) Strains}

The following strains were kindly supplied by Professor Urs Leupold, Institute for General Microbiology, University of Bern, Switzerland:

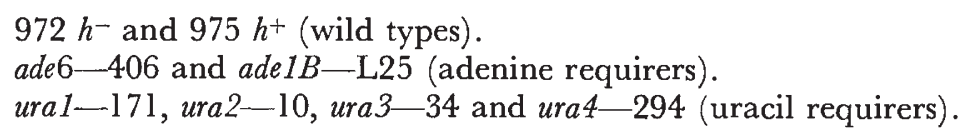

Mutants resistant to cycloheximide were designated cyh. Mutants were considered to have the high resistance phenotype if they showed normal growth after 3-5 days at $30^{\circ}$ on YEA supplemented with $100 \mu \mathrm{g} / \mathrm{ml}(356 \mu \mathrm{M})$ cycloheximide. Mutants which grew slowly at $100 \mu \mathrm{g} / \mathrm{ml}$, but showed normal growth on media supplemented with $40 \mu \mathrm{g} / \mathrm{ml}(142 \mu \mathrm{M})$ cycloheximide after $3-5$ days at $30^{\circ}$ were considered to have the low resistance phenotype.

\section{(ii) Culture media}

Yeast Extract Agar (YEA), Malt Extract Agar (MEA), Minimal Medium Agar (MMA) and synthetic Sporulation Medium Agar (SPA) were prepared according to Gutz et al. (1974). When required, the following supplements were added; to MMA, adenine $(10 \mathrm{mg} / \mathrm{ml})$, uracil $(10 \mathrm{mg} / \mathrm{ml})$ and casamino acids $(250 \mathrm{mg} / \mathrm{l})$; to YEA and MEA, adenine (70 mg/l) and uracil $(70 \mathrm{mg} / \mathrm{l})$. 


\section{(iii) Chemicals}

Cycloheximide, MNNG and 2-deoxy-D-glucose were obtained from Sigma and magdela red from G. T. Gurr. Anisomycin was a gift from Dr J. D. G. Carpenter, Pfizer Ltd., Sandwich, Kent, and trichodermin a gift from Dr Godtfredsen, Leo Pharmaceutical Products, Ballerup, Denmark.

\section{(iv) Determination of the cycloheximide concentration used to select resistant mutants}

Three-day old colonies of $972 h^{-}, 975 h^{+}$and the adenine requiring strains were streaked out on to YEA supplemented with $5,10,20,30,40$ and $50 \mu \mathrm{g} / \mathrm{ml}(18,36,72,107,142$ and $178 \mu \mathrm{M})$ cycloheximide. The plates were incubated at $30^{\circ}$ for up to 10 days. S. pombe was found to be relatively resistant to cycloheximide, $30 \mu \mathrm{g} / \mathrm{ml}(107 \mu \mathrm{M})$ being required to fully prevent growth of the strains used at $30^{\circ}$. Thus a level of $100 \mu \mathrm{g} / \mathrm{ml}$ was routinely used to select mutants.

\section{(v) Isolation of spontaneously occurring cycloheximide-resistant mutants}

In each experiment, cultures of about $10^{7}$ or $10^{8}$ cells derived from a single colony were plated on to five YEA plates containing $100 \mu \mathrm{g} / \mathrm{ml}$ cycloheximide. The plates were incubated at $30^{\circ}$ for up to 10 days. Mutant colonies were classified according to their day of appearance on the plates.

\section{(vi) Isolation of resistant mutants after mutagenic treatment}

Nitrous acid and UV mutagenesis were carried out as described by Clarke (1963). The final concentration of $\mathrm{NaNO}_{2}$ was $0 \cdot 1 \mathrm{M}$. The UV lamp was a TUV Philips 500 tube delivering $40 \mathrm{erg} / \mathrm{mm}^{2} / \mathrm{sec}$. Mutagenesis by MNNG and auxotrophic enrichment by 2-deoxy-D-glucose were carried out according to the method of Megnet (1965). Nitrous acid, UV and MNNG induced resistant colonies were selected and classified according to both the duration of treatment and the day of appearance.

\section{(vii) Qualitative tests on isolated mutants}

Replica plating techniques were used to test for resistance toward cycloheximide, trichodermin and anisomycin and for temperature sensitivity at $14^{\circ}, 25^{\circ}$ and $36^{\circ}$.

\section{(viii) Genetic analysis}

Methods for random spore analysis, tetrad analysis and the synthesis of diploid cells were as described by Gutz et al. (1974).

Tests for allelism: 25 per cent sensitive progeny colonies from crosses between two resistant mutants were taken to indicate that two separate genes were involved. To see whether the temperature sensitive and cycloheximide resistant phenotypes were caused by mutation in the same gene, all mutants which were both resistant and $t s$ were backcrossed to wild type and the progeny spores scored for growth on YEA at $30^{\circ}$ and $36^{\circ}$ and on YEA plus cycloheximide $(100 \mu \mathrm{g} / \mathrm{ml})$ again at $30^{\circ}$ and $36^{\circ}$. If the results 
were 2:1:1:0 respectively, this was taken to indicate that one gene was conferring both cycloheximide resistance as well as $t s$. If the results were $2: 1: 1: 0 \cdot 5$ this was taken to indicate that one gene was conferring resistance and another gene conferring $t s$. If the results were $2: 2: 1: 1$ this was taken to indicate that one gene was conferring the resistance and the $t s$ phenotype was probably conferred by a cytoplasmic factor. Complementation tests between auxotrophic mutants were carried out by the "criss-cross" technique of Gutz et al. (1974).

\section{RESUlts}

\section{(i) Spontaneously occurring mutants}

Two strains were used in the selection of spontaneously occurring cycloheximide-resistant mutants, namely wild type $972 h^{-}$and an adenine requirer ade6-406 $h^{-}$. Results are summarised in table 1. Thirty-six resistant mutants were isolated in the $972 h^{-}$background, 9 mutants of the $\mathrm{C}$ series which showed high-level resistance and 27 mutants of the A series which showed low-level resistance. The nine $\mathrm{C}$ series mutants were backcrossed to wild type and the progeny spores analysed by tetrad analysis (from 7 to 20 complete tetrads per cross). In each cross the resistance phenotype segregated 2:2 with the sensitive (wild type) phenotype as though it were caused by a single nuclear gene.

From each cross a resistant spore of the $h^{+}$mating type was isolated. All nine mutants were crossed to each other and the products tested by free spore analysis (between 100 and 400 spores per cross being analysed). Very few sensitive recombinants (at most two per cross) were found, indicating that all these mutants were in the same gene. This gene was designated $c y h 1$ and one of the mutants cyhl-G7 chosen as a tester strain.

When five of the A series mutants (all of which have the low-resistance phenotype) were each crossed to the $c y h l$ tester strain, 25 per cent sensitive colonies were produced in every case. One of these mutants, A2, was assigned to a second gene $c y h 2$ and used as a tester strain. When cyh2-A2 was backcrossed to wild type the resistance and sensitive markers segregated $1: 1$ as determined by free spore analysis. When a $h^{+}$resistant spore from this cross was crossed to the other four mutants, very few sensitive colonies were found in 100-400 random spores tested indicating that they were allelic with or closely linked to $c y h 2-\mathrm{A} 2$.

Ten resistant mutants were isolated in the ade 6 background ( $\mathrm{K}$ series), 6 had the high resistance phenotype and were allelic with cyhl-G7. Three had the low-resistance phenotype, two being allelic with cyh2-A2 and the third, $\mathrm{K} 10$, being in a separate gene from $c y h \mathrm{l}$ and $c y h 2$, designated $c y h 3$. On backcrossing cyh3-K10 to wild type the resistance and sensitive markers again segregated $1: 1$ as determined by free spore analysis. Results of qualitative tests on the level of resistance and temperature sensitivity of selected mutants, and the genetic factors which are responsible for the resistance and the $t s$ phenotypes are given in table 1 .

When double mutants carrying the ade 6 and $c y h 1, c y h 2$ and $c y h 3$ genes respectively were backcrossed to wild type and the progeny spores analysed by free spore analysis, the $c y h^{\mathbf{R}}$ and ade 6 genes segregated independently in each case. The segregation of mating type and cyh genes was followed in the same crosses and again found to be independent. 

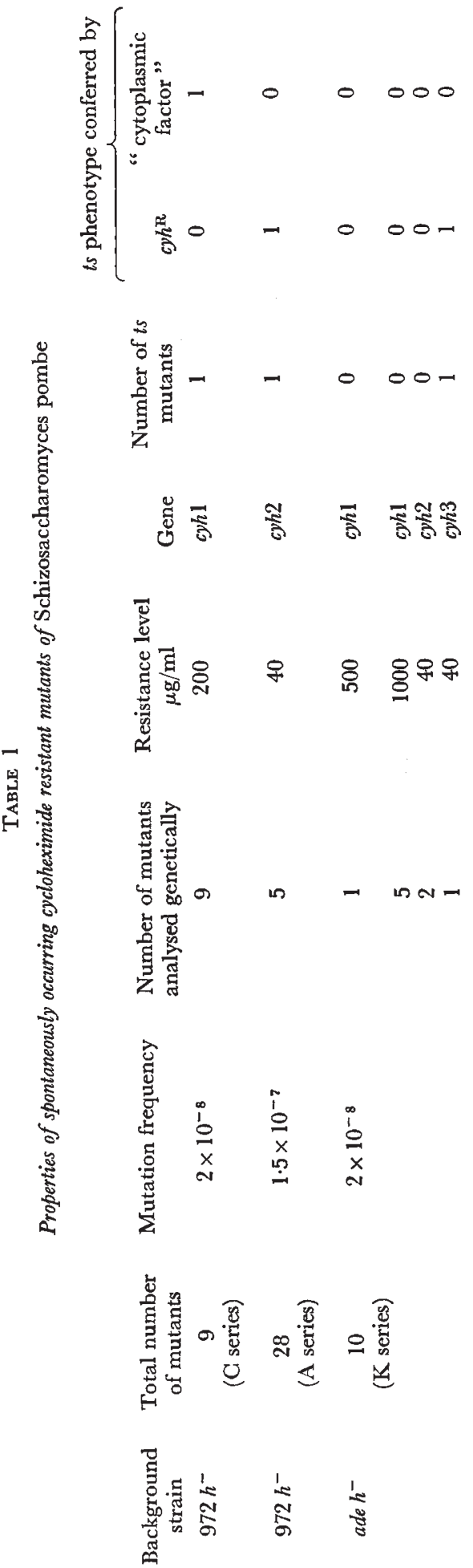
Four resistant mutants (including both low- and high-level types) also possessed the $t s$ phenotype. Random spore analysis of backcrosses of mutants with the $t s$ phenotype to wild-type indicated that, for both cyh2Al6 and $c y h 3-\mathrm{K} 10$, the same locus conferred both the $t$ and resistant phenotypes, whereas the $t s$ phenotype of both cyhl-C8 and cyhl-K7 was lost in the progeny and was therefore assumed to be due to cytoplasmic factors.

Tetrad analysis was carried out for the cross cyhl-C8 $h^{-} \times 975 h^{+}$to confirm spore viability and the validity of the result of the random spore analysis. Thirteen complete tetrads were analysed; the results were in accordance with those obtained on free spore analysis, the $t s$ phenotype being lost as before. Thus the $t s$ phenotype in $c y h 1-\mathrm{K} 7$ and cyhl-C8 may be caused by a cytoplasmic factor.

To summarise the results on the spontaneously occurring mutants, twentythree resistant mutants were analysed genetically and three genes were identified, $c y h 1, c y h 2$ and $c y h 3$. Mutants in the $c y h l$ gene showed high levels of resistance, whereas mutants at the cyh 2 and cyh 3 loci showed low levels of resistance. Cyhl, cyh 2 and $c y h 3$ were not linked to either ade 6 or to mating type. Four strains were temperature sensitive, in two of these, both cyhl alleles, the $t s$ phenotype may be caused by a cytoplasmic factor. In the other two, sensitivity was conferred by a mutation at the cyh 2 and cyh 3 loci respectively.

\section{(ii) Mutagen induced mutants}

In an attempt to get a wide variation of mutant types, mutagens with differing modes of action on the genetic material were used to induce resistant mutants. Nitrous acid induces mutants mostly of the base-pair transition type, MNNG induces mutants mostly of the base-pair substitution type (either transitions or transversions), while UV mainly induces mutants of both the base-pair substitution and frame-shift types (Drake, 1970). In bacteria, MNNG acts preferentially at the DNA replication fork (CerdàOlmedo et al., 1968) and induces closely linked double mutants at a high frequency (Guerola et al., 1971). Hence it was hoped that its use in $S$. pombe would give rise to resistant mutants having closely linked auxotrophic markers which might prove useful for subsequent intragenic mapping. A summary of the properties of cycloheximide resistant mutants isolated after mutagenic treatment is shown in table 2.

Eleven resistant mutants induced by nitrous acid ( $\mathrm{S}$ series) were shown by genetic analysis to be allelomorphs of $c y h l$ or closely linked to it. Genetic analysis of 38 resistant mutants induced by UV ( $U$ series) revealed one more gene besides the three already defined. This new locus (cyh4) segregated freely when crossed with the $c y h 1, c y h 2$ and $c y h 3$ tester strains and is represented by only one mutant namely cyh4-U96, which shows the low-level resistance phenotype.

Mutants in the cyhl gene showed generally high-level resistance but some induced by UV were of the low-level resistance type. A similar observation among cycloheximide-resistant mutants in the actA gene of Physarum polycephalum was reported by Haugli et al. (1972). The $t s$ phenotype is observed in two mutants induced by nitrous acid and may be due to cytoplasmic factors, since $t s$ is lost in the progeny spores from backcrosses to wild type. The $t s$ phenotype present in resistant mutants induced by 


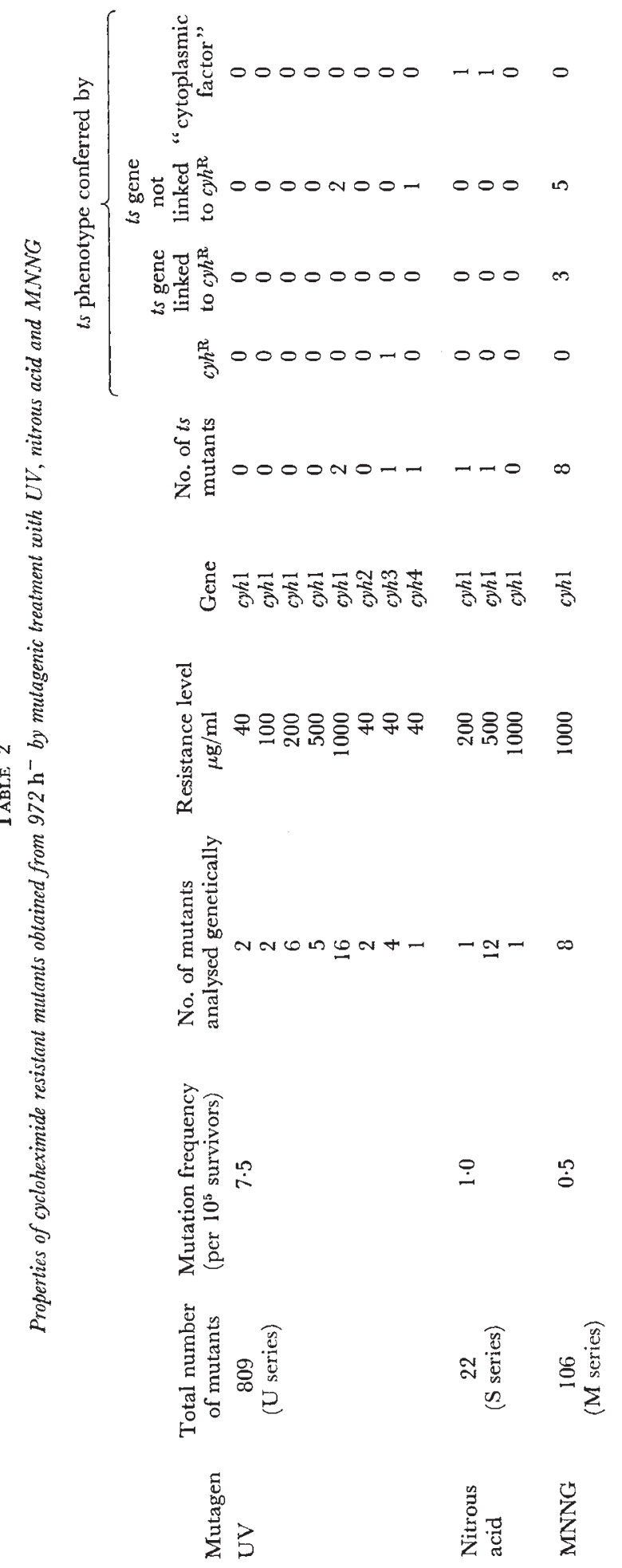


UV mutagenesis is either caused by the same gene (cyh3) or by loci which segregated freely from $c y h^{\mathbf{R}}$ (in the cases of $c y h \mathbf{l}$ and $c y h 4$ ). Eight resistant auxotrophic mutants were isolated from different experiments after MNNG mutagenesis and subsequent enrichment for auxotrophs by treatment with 2-deoxy-D-glucose ( $M$ series). These double mutants were all found to be uracil requirers and could not grow at $36^{\circ}$; genetic crosses to test allelomorphism to the known cyh loci showed them to be alleles of $c y h l$ or closely linked to it.

Backcrosses to wild type of all eight mutants and subsequent free spore analysis showed that the ura locus or loci segregated freely from the cyhl gene. Complementation tests with a tester strain of each of the known ura loci showed that in each case the uracil requirement was due to mutation at one locus, namely ura 4 ; it is interesting to note that both ura 4 and $c y h l$ have been located on linkage group I by haploidisation tests (Kohli, personal communication). The $t s$ phenotype also segregated from the cyhl locus when the strains were backcrossed to wild type, indicating again that a second gene was involved.

Thus to summarise the results of genetic analysis of mutants induced by mutagenic treatment; all mutants analysed could be assigned either to the same three genes found previously or to a new gene cyh4. Several cyhl mutants had the low-resistance phenotype and another $t s$ allele of cyh 3 was obtained. More $c y h l$ mutants were found in which the $t s$ phenotype was lost on backcrossing to wild type. The eight auxotrophic mutants produced by MNNG and subsequent auxotrophic enrichment turned out to be cyhl ura 4 ts triple mutants.

\section{(iii) Dominance tests in diploids}

Diploid cells carrying both mutant and wild type alleles were synthesised for strains carrying $c y h 1, c y h 2, c y h 3$ and $c y h 4$. The genotypes of the diploids were

$$
\begin{aligned}
& \begin{array}{cccccccc}
+ & \text { ade } 6 & c y h 1 & h^{-} & + & \text {ade } 6 & c y h 2 & h^{-} \\
\hline \operatorname{ade} 1 \mathrm{~B} & + & + & h^{-} & \text {adel } & + & + & h^{-}
\end{array} \\
& \begin{array}{lccc}
+ & \text { ade } 6 & c y h 3 & h^{-} \\
\hline \text { ade } 1 \mathrm{~B} & + & + & h^{-}
\end{array} \text {and } \begin{array}{ccccc}
+ & \text { ade } 6 & c y h 4 & h^{-} \\
1 \mathrm{~B} & + & + & h^{-}
\end{array}
\end{aligned}
$$

respectively. Diploid colonies together with haploid strains of $972 h^{--}$, ade 1B-25 $h^{-}$, ade6-406h-, cyhl-K7, cyh2-K8, cyh3-K10 and cyh4-U96, all of $h^{-}$ mating type, were replicated onto YEA plus 40,50 and $100 \mu \mathrm{g} / \mathrm{ml}$ cycloheximide. The tests were repeated at least six times. The results are shown in table 3 . The mutants $c y h l$ and $c y h 4$ are recessive to their wild type allele under the conditions used, whereas $c y h 2$ and $c y h 3$ are semidominant.

\section{(iv) Test for intragenic complementation}

Diploid cells were synthesised for three different alleles of the $c y h 1$ locus, namely $c y h 1-\mathrm{C} 7, c y h l-\mathrm{K} 3$ and $c y h 1-\mathrm{K} 7$, in all possible pairwise combinations. These diploid cells had the genotypes:

$$
\frac{c y h 1-\mathrm{C} 7}{c y h l-\mathrm{K} 3} h^{-}, \quad \frac{c y h 1-\mathrm{C} 7 h^{-}}{c y h 1-\mathrm{K} 7 h^{-}} \text {and } \frac{c y h 1-\mathrm{K} 3 h^{-}}{c y h 1-\mathrm{K} 7 h^{-}}
$$


and showed the same resistance towards cycloheximide as that of the haploids from which they were derived.

TABLE 3

Dominance tests of $\mathrm{cyh}^{\mathrm{R}}$ genes with respect to wild type

\begin{tabular}{lccccc}
\multicolumn{1}{c}{ Strain } & Ploidy & YEA & $\overbrace{40 \mu \mathrm{g} / \mathrm{ml}}$ & $50 \mu \mathrm{g} / \mathrm{ml}$ & $100 \mu \mathrm{g} / \mathrm{ml}$ \\
$972 h^{-}$ & $n$ & ++ & - & - & - \\
adelB-L25 $h^{-}$ & $n$ & ++ & - & - & - \\
ade6-406 $h^{-}$ & $n$ & ++ & - & - & + \\
cyhl-K7 $h^{-}$ & $n$ & ++ & ++ & ++ & + \\
cyh2-K8 $h^{-}$ & $n$ & ++ & ++ & ++ & + \\
cyh3-K10 $h^{-}$ & $n$ & ++ & ++ & + & + \\
cyh4-U96 $h^{-}$ & $n$ & ++ & ++ & ++ & - \\
cyhl-K7 $h^{-} /+h^{-}$ & $2 n$ & ++ & - & - & - \\
cyh2-K8 $h^{-} /+h^{-}$ & $2 n$ & ++ & + & - & - \\
cyh3-K10 $h^{-} /+h^{-}$ & $2 n$ & ++ & + & - & - \\
$c y h 4-\mathrm{U} 96 h^{-} /+h^{-}$ & $2 n$ & ++ & - & - & +
\end{tabular}

Strains were streaked out on YEA and incubated at $30^{\circ}$ for 3 days. They were then replicated on to YEA or YEA plus cycloheximide. + + indicates good growth, + indicates slight growth and - indicates no growth after 2 days at $30^{\circ}$.

\section{(v) Cross resistance toward trichodermin and anisomycin}

Mutants representing all four $c y h^{\mathbf{R}}$ loci were tested for cross resistance to anisomycin and trichodermin, antibiotics which are known to affect translation on the $80 \mathrm{~S}$ ribosome (Grollman, 1967; Cundliffe et al., 1974) and the results are shown in table 4. The alleles of genes with the lowresistance phenotypes (cyh2, cyh3 and cyh 4 ) are cross resistant to both anisomycin and trichodermin. In particular, cyh4 shows greater resistance to trichodermin than do $c y h 2$ and $c y h 3$. One of the $t s$ alleles of $c y h 3$, namely

\section{TABLE 4}

Cross resistance tcreards trichcdeimin and aniscmycin shown by mutants at the $\mathrm{cyh}^{\mathrm{R}}$ loci

\section{Cycloheximide concentration}

at which fully

$972 h^{-}$

cvhl-K $3 h^{-}$

cyhl-Sl $h^{-}$

cvhl-U113 $h^{-}$

cyh2-A $2 h^{-}$

*cy 2 -Al $6 h^{-}$

cyh3-U102 $h^{-}$

*cyh3-U106 $h^{-}$

*cyh3-K10 $h^{-}$ cvh4-U96 $h^{-}$ resistant $\mu \mathrm{g} / \mathrm{ml}$

2
500
1000
40
40
40
40
40
40
40

\begin{tabular}{cccc}
\multicolumn{4}{c}{ YEA plus trichodermin at } \\
\cline { 2 - 4 } YEA & $1 \mu \mathrm{g} / \mathrm{ml}$ & $2 \cdot 5 \mu \mathrm{g} / \mathrm{ml}$ & $5 \mu \mathrm{g} / \mathrm{ml}$ \\
++ & - & - & - \\
++ & - & - & - \\
++ & - & - & - \\
++ & - & - & - \\
++ & ++ & + & - \\
++ & ++ & + & - \\
++ & ++ & - & - \\
++ & ++ & ++ & - \\
++ & ++ & - & - \\
++ & ++ & ++ & +
\end{tabular}

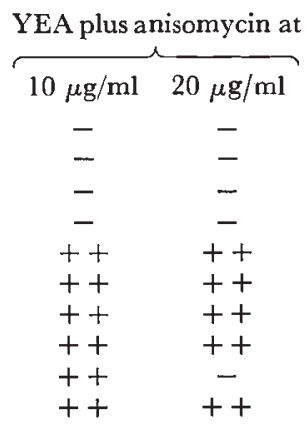

Strains were streaked out on YEA and incubated at $30^{\circ}$ for 3 days. They were then replicated on to YEA, YEA plus trichodermin or YEA plus anisomycin at the concentrations shown above. ++ indicates good growth, + indicates poor growth and - indicates no growth after 2 days at $30^{\circ}$.

* $t s$ mutant in which $t s$ and $c y h^{\mathrm{R}}$ segregate together. 
cyh3-U106, shows a greater resistance to trichodermin than either cyh3-K10 (another $t s$ allele) or cyh3-U102 (not $t s$ ), which show the same degree of resistance. However, cyh3-K10 is sensitive to $20 \mu \mathrm{g} / \mathrm{ml}$ of anisomycin whereas $c y h 3-\mathrm{U} 102$ is not. Mutants at the $c y h l$ gene show the same sensitivity to both drugs as is shown by the wild type, $972 h^{-}$.

\section{(vi) Cold sensitivity and cycloheximide dependence}

The findings of Waldron and Roberts (1974) that some mutants of Aspergillus nidulans originally selected for cold sensitivity, i.e. inability to grow at $20^{\circ}$, were also resistant to cycloheximide, prompted an investigation into the possible cold sensitivity of our cycloheximide-resistant mutants. A representative selection of spontaneously occurring and induced mutants at all cyh loci were tested for their ability to grow at $14^{\circ}$ in both the absence and the presence of cycloheximide $(100 \mu \mathrm{g} / \mathrm{ml})$. The results are shown in table 5 . The majority of the spontaneously occurring and UV-induced

\section{TABLE 5}

Cold sensitivity and cycloheximide dependence shown by mutants at the $\mathrm{cyh}^{\mathbb{R}}$ loci

\begin{tabular}{|c|c|c|c|c|c|}
\hline Mutants & $\begin{array}{l}\text { Number } \\
\text { tested }\end{array}$ & $\begin{array}{l}\text { Resistance } \\
\text { level } \mu \mathrm{g} / \mathrm{ml}\end{array}$ & Gene & $\begin{array}{l}\text { No. of mutants } \\
\text { which are } \operatorname{cs}\left(14^{\circ}\right)\end{array}$ & $\begin{array}{l}\text { No. of mutants which are } \\
\text { cycloheximide dependent at } 14^{\circ}\end{array}$ \\
\hline C series & 9 & $>200$ & $c y h 1$ & 8 & 0 \\
\hline \multirow[t]{4}{*}{$\mathrm{K}$ series } & 1 & 500 & $c y h 1$ & 0 & 0 \\
\hline & 6 & 1000 & $c y h 1$ & 6 & 0 \\
\hline & 2 & 40 & cyh 2 & 2 & 0 \\
\hline & 1 & 40 & cyh3 & 0 & 0 \\
\hline A series & 4 & 40 & $c y h 2$ & 3 & 0 \\
\hline \multirow[t]{8}{*}{$\mathrm{U}$ series } & 15 & 1000 & $c y h 1$ & 10 & 4 \\
\hline & 4 & 500 & $c y h 1$ & 2 & 2 \\
\hline & 6 & 200 & $c y h 1$ & 6 & 1 \\
\hline & 2 & 100 & $c y h 1$ & 2 & 0 \\
\hline & 2 & 40 & cyh 1 & 1 & 0 \\
\hline & 2 & 40 & cyh 2 & 2 & 0 \\
\hline & 4 & 40 & $c y h 3$ & 3 & 0 \\
\hline & 1 & 40 & cyh 4 & 1 & 0 \\
\hline
\end{tabular}

Mutants obtained after nitrous acid and MNNG mutagenesis were neither cold-sensitive nor cycloheximide-dependent.

mutants tested were clearly cold sensitive $(c s)$ at $14^{\circ}$. Some UV-induced cyhl mutants wree both $c s$ and cycloheximide dependent at $14^{\circ}$ - that is in the presence of cycloheximide they would grow normally at this temperature, but without it they showed only slight growth. In crosses between wild type and five cyh mutants of the spontaneously arising G series, cold sensitivity segregated with resistance, indicating that the same mutation confers both phenotypes.

\section{Discussion \\ (i) Mutagenesis}

Cycloheximide-resistant mutants of $S$. pombe are readily obtained either spontaneously or after mutagenic treatment with nitrous acid, UV or 
MNNG. UV appears to give the largest number of different phenotypes and genotypes. Treatment with MNNG, and subsequent enrichment of $c y h^{\mathrm{R}}$ auxotrophs by 2-deoxy-D-glucose, gave triple mutants which were mostly of constitution $c y h \mathrm{l}^{\mathrm{R}}$ ura 4 ts. Since the site of action of MNNG (at least in bacteria) is at the replicating fork, and $c y h^{\mathrm{R}}$, ura 4 and $t s$ are not closely linked, it would seem likely that there are many replicating bubbles on the $S$. pombe chromosome as has been shown to be the case in $S$. cerevisiae (Newlon et al., 1974). If the chromosomes of $S$. pombe were better mapped, it would also seem feasible to use MNNG mutagenesis to locate the positions of replicating forks at various stages in DNA replication as has been suggested for $S$. cerevisiae by Dawes and Carter (1974). In fact, the situation might be simpler in $S$. pombe since perhaps only three (instead of 17) chromosomes are present.

\section{(ii) Mechanism of resistance toward cycloheximide}

Cycloheximide resistance in Schizosaccharomyces pombe can be conferred by mutation in any one of at least four genes. The majority of mutants isolated (66) had high-level resistance and were $c y h 1$ alleles. The rest (17) had the low-level resistance and, of these, two were $c y h l$ alleles, nine were $c y h 2$ alleles and there was one cyh4 allele. On the basis of temperature sensitivity and dominance relationships with respect to wild type in diploids, the genes can be ascribed to two groups. In the first group, comprising $c y h 1$ and $c y h 4$, many $c y h 1$ alleles and the single $c y h 4$ allele were $t s$ but in no case was this conferred by the $c y h^{\mathrm{R}}$ gene. In most cases a second gene was involved, indicating that a double hit had occurred. However, in the case of four alleles of $c y h \mathrm{l}$, the $t s$ phenotype was not transmitted through a backcross to wild type-it simply disappeared. The only explanation we have for this finding it that $t s$ is due to a cytoplasmic factor. Both $c y h 1$ and $c y h 4$ alleles were recessive to wild type in dominance tests in diploids. In the second group, comprising $c y h 2$ and $c y h 3$, joint segregation of the $t s$ and $c y h^{\mathrm{R}}$ phenotypes was found for all $t s$ strains, indicating that a single mutation is responsible for both phenotypes. Dominance tests in diploids showed that $c y h 2$ and $c y h 3$ alleles were semidominant to wild type.

Comparison with other systems would suggest that in the first group resistance is due to altered ribosomes. In Saccharomyces cerevisiae the cyh2 and cyh 8 mutant strains, which are known to possess resistant ribosomes, also have the high-resistance phenotype and are recessive to wild type in diploids. In Physarum polycephalum the actA gene has alleles of both highand low-resistance phenotypes and one highly resistant allele has resistant ribosomes (Haugli et al., 1972). Recent experiments in this laboratory (Berry and Coddington, in preparation) using a poly-U directed cell-free system from Schizosaccharomyces pombe have confirmed that, in the case of one highly resistant $c y h 1$ allele, resistance is a property of the $60 \mathrm{~S}$ ribosome subunit. As far as the other group is concerned, from the phenotypic data it would seem unlikely that resistance is ribosomal. In $S$. cerevisiae alleles at three loci-, cyhl, cyh5 and $c y h 7$, showed the low-resistance phenotype and were semi-dominant to wild type in diploids (Wilkie and Lee, 1965). Resistance in these strains was subsequently shown not to be a property of the ribosome (Cooper et al., 1967). If resistance is not ribosomal in our cyh 2 and cyh 3 strains, then it could be due to a reduced permeability 
for the drug or to it being converted to a non-toxic product. The first possibility seems particularly attractive since it could account both for the low-resistance phenotype and to the fact that these strains are also cross resistant to anisomycin and trichodermin. If the cyh2 and cyh3 genes specified some component of the cell membrane then they would be expected to have an effect on the uptake of more than one compound. Biochemical experiments are now in progress to test these hypotheses concerning the mode of action of the cyh 2 and $c y h 3$ genes.

The cyh4 strain, which on phenotypic evidence discussed earlier would appear to be a candidate for ribosomal resistance, is much more cross resistant to anisomycin and trichodermin than the cyh2 and $c y h 3$ strains and we have evidence that this strain is basically a trichodermin resistant mutant which is also cross resistant to anisomycin and cycloheximide. The lack of cross resistance to anisomycin and trichodermin shown by cyhl alleles suggests that this gene is uniquely involved in conferring resistance towards cycloheximide.

\section{(iii) Cold sensitivity}

The majority of mutants tested, at all loci, were found to be cold sensitive at $14^{\circ}$. On the other hand, cycloheximide dependence at the same temperature was shown only by a few cyhl alleles. In the case of $5 c y h 1$ alleles, cs and $c y h^{\mathbf{R}}$ segregated together when backcrossed to wild type. This property of $c y h^{\mathbf{R}}$ also leading to $c s$ could prove useful in fine structure mapping of the cyhl gene since it would avoid the necessity of looking for a few cycloheximide-sensitive recombinants among many resistant spores. Waldron and Roberts (1974) have shown that many cs mutants of Aspergillus nidulans are also $c y h^{\mathbf{R}}$. Four $c s$ mutants in this organism, representing three loci, were shown to produce decreased amounts of the $60 \mathrm{~S}$ ribosomal subunit. Two of these were cycloheximide-resistant, $c s$ and $c y h^{\mathbf{R}}$ segregating together. The authors suggested that a defective ribosomal protein could be responsible for both phenotypes. The same explanation would also fit the data presented here.

Acknowledgments. - We thank Miss Lynda Flegg for her excellent technical assistance, the Government of Iraq for a research studentship to M. A. K. I., Mr Jürg Kohli for access to his mitotic haploidisation data and finally Professor Urs Leupold for introducing us to $S$. pombe and for his advice and enthusiasm for our project.

\section{REFERENGES}

BRUSICK, D. J. 1972. Induction of cycloheximide resistant mutants in Saccharomyces cerevisiae with N-methyl-N'-nitro-N-nitrosoguanidine and ICR-170. F. Bact., 109, 1134-1138.

CERDÀ-OLMEDO, E., HANAWALT, P. C., AND GUEROLA, N. 1968. Mutagenesis of the replication point by nitrosoguanidine: map and pattern of replication of the Escherichia coli chromosome. 7. Mol. Biol., 33, 705-719.

CLARKE, C. H. 1963. Suppression by methionine of reversions to adenine independence in Schizosaccharomyces pombe. F. Gen. Microbiol., 31, 353-363.

COOPER, D., BANTHORPE, D. V., AND WILKIE, D. 1967. Modified ribosomes conferring resistance to cycloheximide in mutants of Saccharomyces cerevisiae. 7. Mol. Biol., 26, 347-350.

CUNDliffe, E., GANNON, M., AND DAvies, J. 1974. Mechanisms of inhibition of eukaryotic protein synthesis by trichothecene fungal toxins. Proc. Nat. Acad. Sci., (USA)., 71, 30-34.

DAWES, I. W., AND CARTER, B. L. A. 1974. Nitrosoguanidine mutagenesis during nuclear and mitochondrial gene replication. Nature, 250, 709-712. 
DEE, J. 1966. Genetic analysis of actidione resistant mutants in the myxomycete Physarum polycephalum schw. Genet. Res., Camb., 8, 101-110.

DEE, J., AND POULTER, R. J. 1970. A gene conferring actidione resistance and abnormal morphology on Physarum polycephalum plasmodia. Genet. Res., Camb., 14, 35-41.

DRAKE, J. w. 1970. The Molecular Basis of Mutation. Holden and Day, San Francisco.

GROLLMAN, A. P. 1967. Inhibitors of protein biosynthesis. II. Mode of action of anisomycin. F. biol. Chem., 242, 3226-3233.

GUerola, N., ingRAham, J. L., AND GERDA-OLMEDo, E. 1971. Induction of closely linked multiple mutations by nitrosoguanidine. Nature, 230, 122-125.

GUTZ, H., HESLOT, H., LEUPOLD, U., AND LOPRIENO, N. 1974. "Schizosaccharomyces pombe". In Handbook of Genetics (ed. R. C. King), Vol. 1, pp. 395-446. Plenum Press, New York and London.

haugli, F. B., DOVE, W. F., AND Jimenez, A. 1972. Genetics and biochemistry of cycloheximide resistance in Physarum polycephalum. Molec. gen. Genet., 118, 97-107.

HOWE, H. B., AND TERRY, c. E. 1962. Genetic studies of resistance to chemical agents in Neurospora crassa. Can. F. genet. Cytol., 4, 447.

HSU, K. s. 1963. The genetic basis of actidione resistance in Neurospora. F. gen. Microbiol., 32, 341-347.

IBRAHIM, M. A. K., AND CODdington, A. 1974. Cycloheximide resistant mutants of Schizosaccharomyces pombe. Heredity, 33, 141.

JIMENEZ, A., LITTLEWOOD, B., AND DAVIES, J. 1972. Inhibition of protein synthesis in yeast. In Molecular Mechanisms of Antibiotic Action on Protein Synthesis and Membranes (eds. E. Munoz, F. Garcia-Fernandez and D. Vazquez), pp. 292-306. Elsevier, Amsterdam. MEGNET, R. 1965. Screening of auxotrophic mutants of Schizosaccharomyces pombe with 2-deoxy-D-glucose. Mut. Res., 2, 328-331.

MidDLEKAUF, J. E., MiNO, s., YANG, s. P., LINDEGREN, G., AND LiNDEGREN, c. c. 1957. Gene control of resistance vs sensitivity to actidione in Saccharomyces. Genetics, 59, 327-333.

NEUHÄUSER, A., KLINGMÜLLER, W., AND KAUDEWITZ, F. 1970. Selektion actidion resistenter Mutanten bei Neurospora crassa sowie ihr genetische und biochemische Analyse. Molec. gen. Genet., 106, 180-194.

NEWLON, C. S., PETES, T. D., HEREFORD, L. M., AND FANGMAN, W. L. 1974. Replication of yeast chromosomal DNA. Nature, Lond., 247, 32-35.

PONGRATZ, M., AND KLINGMÜLLER, w. 1973. Role of ribosomes in cycloheximide resistance of Neurospora mutants. Molec. gen. Genet., 124, 359-363.

RAO, S. S., AND GROLLMAN, A. P. 1967. Cycloheximide resistance in yeast: a property of the 60 S ribosomal sub-unit. Biochem. Biophys. Res. Commun., 29, 696-704.

ROBERTS, C. H. T., AND ORIAS, E. 1973. A cycloheximide resistant mutant of Tetrahymena pyriformis. Exp. Cell. Res., 81, 312-316.

SIEGEL, M. R., AND SISLER, H. D. 1965. Site of action of cycloheximide in cells of Saccharomyces pastorianus. II. Further studies on the mechanism of action and the mechanism of resistance in Saccharomyces species. Biochim. Biophys. Acta, 103, 558-567.

vomvoyanni, v. 1974. Multigenic control of ribosomal properties associated with cycloheximide sensitivity in Neurospora crassa. Nature, Lond., 248, 508-510.

WALDRON, C., AND ROBERTs, C. F. 1974. Cold sensitive mutants in Aspergillus nidulans. II. Mutants affecting ribosome production. Molec. gen. Genet., 134, 115-132.

WARR, J. R., AND ROPER, J. A. 1965. Resistance to various inhibitors in Aspergillus nidulans. 7. gen. Microbiol., 40, 273-281.

WILKIE, D., AND LEE, B. K. 1965. Genetic analysis of actidione resistance in Saccharomyces cerevisiae. Genet. Res., Camb., 6, 130-138. 